\title{
Organisation of local actors and data reporting in veterinary public health
}

\author{
Sofia Mlala ${ }^{1}$, François Dedieu² ${ }^{2}$ Viviane Hénaux ${ }^{1}$ \\ ${ }^{1}$ University of Lyon, French Agency for Food, Environmental and Occupational Health \& Safety (ANSES), Laboratory of Lyon, Lyon, France, \\ ${ }^{2}$ Interdisciplinary Laboratory for Science, Innovations and Societies (LISIS), University of Paris, Champs-sur-Marne, France
}

\section{Objective}

The objectives were to understand the functioning of the local network of actors involved in the French bovine infectious diseases surveillance system and the influence of their organisation on data reporting from the field.

\section{Introduction}

Disease surveillance systems can be based on two components of surveillance: active surveillance in which the diseases are looked for on a regular basis in a defined population, and passive surveillance where the diseases are looked for whenever specific sanitary events are notified. The first type of surveillance is fundamental to detect clinically unexpressed infections and to estimate the prevalence of the disease in the global population. The second type of surveillance is essential to detect new disease cases as early as possible after their appearance, and necessitates a clinical expression of infections. Active surveillance is more complete but also takes more resources to be implemented. As for passive surveillance, although it has the advantage of sparing resources, it is subject to variability in data reporting according to the reporters. A recent study was conducted in France on a specific data reporting in veterinary public health: the declaration of bovine abortions [1]. It is the main clinical sign for some diseases that can have a serious economic impact on the production and that can be transmittable to humans. This study has highlighted individual obstacles to abortion declaration by farmers and veterinarians, but it has also shown that in different departments of France with the same bovine farming characteristics (similar types of production, mean sizes of the farms, density of farms, etc.), large differences could be observed regarding their abortion declaration rate (a department is a French administrative and territorial division covering a mean surface area of $5,800 \mathrm{~km}^{2}$ ). This result suggests that there is another level of factors influencing data reporting, different from the individual factors related to the characteristics of the farms. We formulated the hypothesis that these other factors were related to the local governance of animal health surveillance data collection.

Our study was thus developed in the continuity of this previous research to explore the variation of data reporting in relation with the organisation of animal health surveillance actors of bovine production at the local level. In France, an official organisation chart sets how actors should act and interact with one another at the national, regional and departmental scales, and yet some differences can be observed at the departmental level, mostly regarding the relations between actors, due to a difference in the resources available for each actor according to the local context.

\section{Methods}

We used the methodology and tools of Sociology of Organisations [2]. A series of 34 semi-structured interviews were conducted in spring and summer 2018 with the animal health surveillance actors of two French departments (respectively, 16 and 18 interviews).

The two departments were chosen with similar bovine farming characteristics (both mixed production types, similar mean size and number of herds) in order to reduce the influence of this factor on data reporting. We also looked for different levels of data reporting, through their respective abortion declaration rates, based on the data available in a national database.

In both departments, the interviewees were bovine farmers, rural veterinarians, representatives of farmers' and veterinarians' organisations and of departmental veterinary laboratories, departmental veterinary services and departmental councils (Figure 1). The material collected was analyzed by creating sociograms that characterized roles and interdependences between actors. Then, the underlying mechanisms were identified and related to the level of data reporting. 


\section{Results}

Our results showed evidence of the central position of veterinarians in the network of actors, as all major surveillance actors needed either their expertise of veterinary medicine or their proximity to farmers as an important resource for their action. There was complementarity and good collaboration between veterinarians and the farmer health-support association in both departments. Nevertheless, veterinarians wanted to remain the reference actor in all farms regarding sanitary issues and they had an advan tage over the farmer health-support association in one of the two departments studied, where the membership rate to the health-support association was less high. Veterinarians also had to face another form of competition, which was more obvious, from some farmer organisations and cooperatives that have an official delegation for the sale of veterinary medicine. In the two departments of the study, the place taken by these organisations on the medicine market was very different and so was the pressure exerted by this competition on veterinarians' activities.

In one of the two departments studied, there was a specific form of organisation between veterinary clinics and farmers that materialised by an association between them. In this setting, they agreed on an annual package that covered the most frequent veterinary acts for a fixed price. The veterinarians of these associations also organised regular trainings for farmers, to enable them to dispense primary care to their animals. In these specific forms of organisation, there were a lot of exchanges and trust between farmers and their veterinarians, which diminished their asymmetry of competence (as typically observed in a patient-to-doctor relation), to approach a more collaborative relation.

\section{Conclusions}

These first results show interesting discrepancies at the local level between the forms of organisation and the nature and force of the relations between veterinary public health actors. In the following of the analysis, we will concentrate on the impact of these identified differences on the quality of data reporting. We aim to identify conditions that foster a fluent and sustainable communication of surveillance information between actors. These conditions would thus facilitate data reporting from the field, which is a key component of the surveillance systems, enabling a precocious detection of new disease infections.

In public health as well as veterinary public health, a better understanding of the local forms of organisation and the way they influence data circulation between actors helps creating and improving surveillance systems in a way that is more adapted to the field situations, sometimes different from what theory foresees. This is made possible by an interdisciplinary approach between sociology and epidemiology in disease surveillance.

\section{Acknowledgement}

I am grateful to all the people who generously gave their time to contribute to the sociological survey.

\section{References}

1. Bronner A, Hénaux V, Fortané N, Hendrikx P, Calavas D. 2014. Why farmers and veterinarians do not report all bovine abortions, as requested by the clinical brucellosis surveillance system in France? BMC Vet Res. 10, 93-104. PubMed https://doi.org/10.1186/1746-6148-10-93

2. Friedberg E. Le pouvoir et la règle. Dynamiques de l'action organisée. ed. Paris: Le Seuil; 1993. French. 


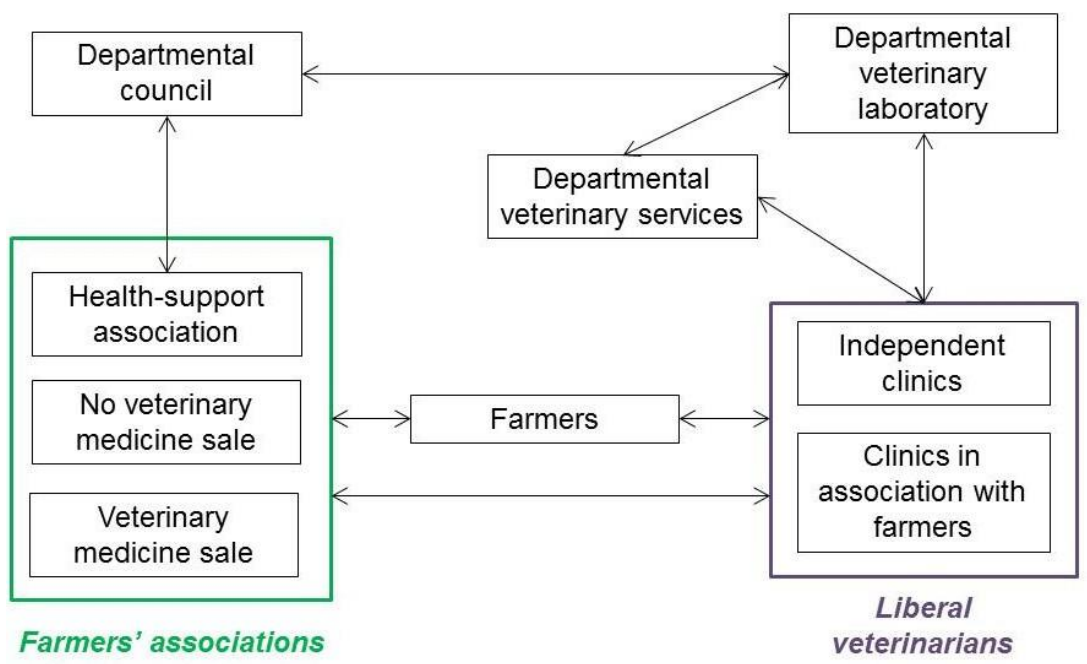

Figure 1. Schema of the relations among the main actors involved in animal health surveillance in France. 